\title{
LETRAMENTO ESTATÍSTICO: UMA PROPOSTA DE ENSINO REMOTO EM TEMPOS DE PANDEMIA
}

\section{STATISTICAL LITERACY: A PROPOSAL FOR REMOTE EDUCATION IN PANDEMIC TIMES}

\author{
Cecy Leite Alves Carreta \\ Universidade Cruzeiro do Sul - UNICSUL \\ cecy@hotmail.com.br \\ Sidney Silva Santos \\ Universidade Cruzeiro do Sul - UNICSUL \\ sidneysantosnm@,gmail.com \\ Geovane Carlos Barbosa \\ Universidade Cruzeiro do Sul - UNICSUL \\ geovanebc@gmail.com
}

\begin{abstract}
Resumo
O presente artigo tem por objetivo promover indícios de Letramento Estatístico em um grupo de estudantes dos $6^{\circ}$ e $7^{\circ}$ anos do Ensino Fundamental da rede pública municipal da cidade de São Paulo. Para a coleta de dados, uma sequência de atividades foi planejada com foco nos efeitos provocados pelo novo coronavírus e aplicada em um ambiente virtual. A investigação foi estruturada levando em consideração a pesquisa qualitativa no qual recorremos ao Letramento Estatístico para fundamentarmos nossas escolhas. Analisando os resultados percebemos que houve uma contribuição para o desenvolvimento do Letramento Estatístico em alguns desses estudantes, uma vez que observamos a presença do pensamento crítico na tomada de decisões estatísticas frente a problemas reais.
\end{abstract}

Palavras-chave: Educação Estatística; Letramento Estatístico; Ensino Remoto; Sequência de Atividades.

\begin{abstract}
This article aims to promote evidence of Statistical Literacy in a group of students from the 6th and 7th grades of elementary school in the municipal public schools in the city of São Paulo. For data collection, a sequence of activities was planned focusing on the effects caused by the new coronavirus and applied on a virtual environment. The investigation was structured taking into account the qualitative research in which we called upon Statistical Literacy in order to support our choices. Analyzing the results, we realized that there was a contribution to the development of Statistical Literacy in some of these students, since we observed the presence of critical thinking in making statistical decisions in the face of real problems.
\end{abstract}

Keywords: Statistical Education; Statistical Literacy; Remote Teaching; Sequence of Activities. 


\section{INTRODUÇÃO}

A educação atualmente enfrenta diversos desafios para se adaptar à realidade do isolamento social. As aulas deixaram de acontecer de forma presencial, para serem oferecidas de forma remota, em ambientes virtuais síncronos e assíncronos. Paralelamente a essa realidade, deparamos com o desafio de reinventar nossa prática pedagógica na intenção de contribuir para o desenvolvimento individual e coletivo dos estudantes.

Deste modo, muitos desafios surgem ao se pensar em aulas virtuais, por um lado, a preocupação com a aprendizagem das crianças; as devolutivas das atividades; o domínio de recursos tecnológicos disponíveis na internet e o auxílio para as crianças familiarizar-se com a plataforma. Por outro lado, a falta de acesso dos estudantes à plataforma Google Classroom, impossibilita a interação e comunicação com o professor e, principalmente, na execução das atividades propostas.

Contudo, propomos uma sequência de atividades criadas e aplicadas em um ambiente virtual, o qual vem sendo utilizado por professores da rede municipal da cidade de São Paulo, o Google Classroom. A sequência constitui de uma série de atividades envolvendo discussões e reflexões sobre a pandemia provocada pelo novo coronavírus - COVID 19, as quais contribuem para o desenvolvimento do Letramento Estatístico. Dessa forma, o aluno é considerado o centro do processo educacional no qual aprimora o seu espírito investigativo, criativo, argumentativo e, principalmente, criativo.

Este estudo tem por objetivo promover indícios de Letramento Estatístico em estudantes dos $6^{\circ}$ e $7^{\circ}$ anos para contribuir com postura fundamentada em dados contextualizados e, a partir deles, tomar decisões conscientes e realizar avaliações críticas contidas em informações estatística veiculadas pela mídia em relação à pandemia. Como forma de promover o Letramento Estatístico as atividades foram planejadas com foco no contexto social do aluno marcado atualmente pela pandemia. Essa sequência permitiu aos alunos coletar, organizar, construir e interpretar informações reais.

As atividades presentes neste artigo foram intituladas (1) "Dados Estatísticos: Novo coronavírus"; (2) "Reflexões sobre o retorno às aulas presenciais" e (3) "A realidade da minha escola", que foram aplicadas com estudantes de três turmas do $6^{\circ}$ ano e uma do $7^{\circ}$ ano de uma escola municipal da cidade de São Paulo. Utiliza como recurso o Google Classroom e a sequência de atividades pode ser adaptada e aplicada para os ciclos 
interdisciplinares (do $4^{\circ}$ ao $6^{\circ}$ ano), autoral $\left(7^{\circ}\right.$ ao $9^{\circ}$ ano) e para o Ensino Médio.

\section{ENSINO REMOTO: CONTEXTO ATUAL}

Diante dos novos desafios enfrentados pela sociedade, as novas propostas de uma educação de qualidade na modalidade remota, tem sido uma possível solução frente a um momento de mudança de paradigma educacional. Uma dessas mudanças mais significativas foi declarada no Brasil, em março de 2020, quando o governo decretou estado de calamidade pública em virtude da pandemia do novo coronavírus (COVID-19). Assim, os efeitos provocados pela pandemia não ficaram restritos somente às pessoas infectadas, mexeu com todos os setores existentes, principalmente, na educação.

Dessa forma, o cenário atual da educação necessita das tecnologias digitais mais do que nunca, visto que a descoberta da Covid-19 submeteu todos os alunos da rede municipal de São Paulo ao ensino de forma remota, pelo intermédio da tecnologia, como forma de complementar o material impresso disponibilizado pela Secretaria Municipal de Educação. O Ensino Remoto foi criado com o intuito de dar continuidade ao processo de ensino, para minimizar os efeitos do isolamento social na educação. Nele os professores oferecem acolhimento aos estudantes e continuidade em sua escolarização.

Nesse contexto pandêmico, as aulas ocorrem em salas virtuais, por intermédio da tecnologia e possuem características próprias. Casatti (2020) aponta que as salas de aula virtuais apresentam uma dinâmica própria de interação, além de necessitar de características pedagógicas diferentes, por isso, esse cenário é um grande desafio para todos os envolvidos.

As escolas municipais da cidade de São Paulo estão contando como principal alternativa para esse momento, a distribuição de materiais impressos criado especialmente para esse momento de isolamento social, intitulado por Trilhas de Aprendizagens (volume 1 e 2), conta com propostas de atividades de cada componente curricular, além disso, os professores postam atividades e materiais, de caráter complementar, no Google Classroom o que possibilita a comunicação com a criança de forma síncrona e assíncrona.

Os momentos síncronos são aqueles em que o professor interage com a turma em tempo real por meio das salas de bate-papo e Google Meet; os assíncronos são aqueles em que o professor e o aluno se comunicam a medida que possuírem tempo hábil por meio do mural, comentário particular, comentário da turma e Google planilha disponível no ambiente 
virtual Google Classroom.

As maiores dificuldades encontradas durante a realização das atividades, no ensino remoto ocorriam por conta da barreira dos alunos na utilização das ferramentas da plataforma, porém, também foram encontrados obstáculos na comunicação entre professora e alunos, visto que a professora optou por utilizar apenas a comunicação assíncrona por meio das ferramentas: comentário particular, mural e os formulários. Essa escolha fez com que o diálogo demorasse mais e a utilização da comunicação, apenas, por meio da digitação limitou as discussões.

Outro fator que vale ressaltar das dificuldades encontradas no ensino remoto está associado ao impedimento de acesso dos alunos, muitos não realizaram as atividades por não terem acesso à plataforma por diversos motivos, alguns não possuem aparelhos eletrônicos adequados e/ou internet de qualidade, sendo impossibilitados de participar das atividades propostas de forma integral ou parcial, porém, consideramos que mesmo os alunos que conseguiram participar parcialmente das atividades avançaram de forma significava na promoção dos indícios do Letramento Estatístico, visto que cada atividade possui um objetivo individual que avança para esse conhecimento.

A escola que foi aplicada essas atividades tem a organização, durante o ensino remoto, de postar apenas uma atividade semanal por componente curricular na plataforma. Então, a disciplina de Matemática é postada apenas na segunda-feira, por isso, a atividade foi aplicada durante nove semanas. A sequência de atividades foi disponibilizada individualmente para cada aluno e foram ofertados recursos audiovisuais e vídeos disponíveis na internet para fomentar a discussão acerca dos apontamentos levantados durante a realização das atividades.

\section{LETRAMENTO ESTATÍSTICO}

O mundo à nossa volta é repleto de informações e situações que permitem recorrer à estatística para resolver os problemas relacionados às diferentes áreas do conhecimento ou para inferir criticamente sobre eles.

Segundo Lopes (2008, 2010), nas últimas décadas, os currículos de Matemática da maioria dos países inseriram conteúdos de Combinatória, Probabilidade e Estatística, desde os anos iniciais da escolarização fundamental de um estudante. No Brasil, o ensino desses 
conteúdos foi implementado de forma sugestiva por meio do tema "Tratamento da Informação” denominado no Parâmetro Curricular Nacional do Brasil (1997) e, em Brasil (2017), com a implementação da Base Nacional Comum Curricular, agora como uma unidade temática específica intitulada "Probabilidade e Estatística", a qual normatiza que o ensino de estatística e probabilidade deve ser abordado a partir dos anos iniciais do Ensino Fundamental.

Este documento oficial enfatiza que os estudantes dos $6^{\circ}$ anos devem desenvolver, dentro dessa temática, a habilidade de

Identificar as variáveis e suas frequências e os elementos constitutivos (título, eixos, legendas, fontes e datas) em diferentes tipos de gráficos; interpretar e resolver situações que envolvam dados de pesquisas sobre contextos ambientais, sustentabilidade, trânsito, consumo responsável, entre outros, apresentadas pela mídia em tabelas e em diferentes tipos de gráficos. Além disso, o documento solicita aos alunos redigir textos escritos com o objetivo de sintetizar conclusões; Planejar e coletar dados de pesquisa referente a práticas sociais escolhidas pelos alunos e fazer uso de planilhas eletrônicas para registro, representação e interpretação das informações, em tabelas (BRASIL, 2017, p. 305).

Para os alunos dos $7^{\circ}$ anos são esperadas as habilidades de

Planejar e realizar pesquisa envolvendo temas da realidade social, identificando a necessidade de ser censitária ou amostral, e interpretar os dados para comunicálos por meio de relatório escrito, tabelas e gráficos, com o apoio de planilhas eletrônicas; interpretar e analisar dados apresentados em gráfico de setores divulgados pela mídia e compreender quando é possível ou conveniente sua utilização (BRASIL, 2017, p. 311).

Paralelamente a este cenário, emergem algumas preocupações e desafios sobre o que ensinar e como ensinar os conteúdos relacionados a essas temáticas para o desenvolvimento do pensamento científico, da comunicação estatística e probabilística, da argumentação fundamentada e da tomada de decisão consciente. Concomitantemente ao desafio de ensinar e aprender probabilidade e estatística, sobreveio também a necessidade de romper com os aspectos procedimentais das aulas de matemática que valorizam fórmulas, cálculos e regras.

Entendemos, assim como Cazorla, Kataoka e Silva (2010), que o ensino de probabilidade e estatística se dá por meio do desenvolvimento de competências como o Letramento Estatístico, que tem por intuito proporcionar uma postura focada na investigação e reflexão crítica, uma vez que estamos inseridos em uma sociedade globalizada, carregada de informações e pela necessidade de tomar decisões em situações de incerteza.

Isso remete a considerar que o Letramento Estatístico está relacionado com

à habilidade de comunicação estatística, que envolve ler, escrever, demonstrar e

ReviSeM, Ano 2021, N. 1, p. 169-190 
trocar informações, interpretar gráficos e tabelas e entender as informações estatísticas dadas em jornais e outras mídias, sendo capaz de se pensar criticamente sobre elas (CAMPOS, WODEWOTZKI, JACOBINI, 2011, p. 44).

Nessa perspectiva, para letrar o estudante, precisamos envolvê-lo no processo de aprendizagem proporcionado o contato com informações estatísticas reais possibilitando coletar, organizar, interpretar, tirar conclusões e, a partir delas, tomar decisões pautadas em dados. Dessa forma, Gal (2002) argumenta que uma criança, um jovem ou um adulto se constitui letrada estatisticamente quando consegue realizar interpretações e análises críticas sobre informações estatísticas apresentadas em uma ótica social globalizada.

O contexto atual, a qual fomos submetidos, requer, mais que nunca, cidadãos letrados para decifrar as informações estatísticas contidas em textos escritos ou orais, por meio de números e símbolos e sob a forma de gráficos e tabelas de maneira crítica e argumentar sobre elas deixando de lado as crenças e atitudes construídas por meio do senso comum (GAL, 2002).

Dessa forma, entendemos, que é preciso:

Analisar/relacionar criticamente os dados apresentados, questionando/ponderando até mesmo a sua veracidade. Assim, como não é suficiente ao aluno desenvolver a capacidade de organizar e representar uma coleção de dados, faz necessário interpretar e comparar esses dados, faz-se necessário interpretar e comparar esses dados para tirar conclusões (LOPES, 2008, p. 60).

Direcionamos as atividades, que compõem esse artigo, a fim de promover indícios do Letramento Estatístico, no qual os alunos possam compreender de forma crítica as informações presentes na mídia, para então tomar decisões e argumentar os seus pontos de vista, baseando suas decisões em uma análise crítica dos dados que estão postos. Para o Letramento Estatístico, é importante que o aluno tenha autonomia na escolha da pesquisa para criar seus próprios dados e então compará-los com os apresentados em jornais (impressos ou digitais), TV e Internet. Assim, a atividade presente neste artigo, zela pelo poder de decisão, investigação e argumentação dos estudantes.

\section{PROCEDIMENTOS METODOLÓGICOS}

Nossa investigação se concentra em uma análise qualitativa pois acreditamos que essa abordagem permite ao pesquisador investigar "o universo dos significados, dos motivos, das aspirações, das crenças, dos valores e das atitudes" (MINAYO, 2010, p. 20) presente no contexto escolar. 
A sequência de atividades teve como intuito proporcionar aos alunos o poder de decisão. Além disso, também promove o poder de argumentação por meio da Língua Portuguesa. A estatística é considerada por Brasil (2017) um componente curricular estudado dentro da matemática, deste modo, as crianças deste nível de escolaridade, não percebem que a estatística é uma ciência particular, motivo que nos levou a utilizar o termo matemática/estatística como uma referência à estatística, visto que o nome da disciplina é Matemática.

Diante do cenário apresentado, a atividade foi aplicada para alunos do $6^{\circ}$ ano e $7^{\circ}$ ano do Ensino Fundamental em uma escola da Rede Municipal de São Paulo, entretanto a última atividade (A realidade da nossa escola) foi aplicada apenas para os alunos do $7^{\circ}$ ano, visto que os $6^{\circ}$ anos tiveram uma demanda referente a abordagem de outros conteúdos para complementar o material impresso Trilhas de Aprendizagens. Todas as atividades descritas nesta pesquisa foram propostas para 129 estudantes de uma escola da rede municipal de São Paulo. Porém, desse total, apenas 27 alunos realizaram a devolutiva da atividade na qual trazemos para compor a base de dados para análise deste estudo. Logo, as atividades relatadas neste artigo foram frutos de um curso promovido pela Sociedade Brasileira de Educação Matemática Paulista (SBEM/SP), em parceria com a Centro de Estudos e Pesquisa em Educação Matemática e Estatística - CEPEME associado à Universidade Cruzeiro do Sul, intitulado "Práticas pedagógicas em Educação Estatística para anos finais do Ensino Fundamental" coordenado pela professora Dra. Celi Espasandin Lopes e pelos professores Ms. Sidney Silva Santos e Ms. Geovane Carlos Barbosa. As atividades foram desenvolvidas por meio da plataforma Google Classroom, utilizando os recursos de planilhas eletrônicas, texto, mural e formulário.

Assim, as atividades implementadas objetivam a promoção do Letramento Estatístico com uma leitura consciente de dados, um olhar crítico sobre a pandemia e argumentação sobre o retorno das aulas presenciais. O tempo de desenvolvimento foi de nove semanas, uma vez que cada uma das atividades - Dados estatístico - Novo coronavírus; Reflexão sobre o retorno das aulas e A realidade da minha escola - foram divididas em três partes, ou seja, a sequência inteira contou com nove partes, e cada parte foi separada como uma atividade no Google Classroom. Portanto, essa separação se fez necessária por conta da dificuldade apresentada pelos alunos na utilização dos recursos da plataforma. 
As turmas de aplicação da atividade contaram com alunos participativos, que se mostraram engajados no desenvolvimento das atividades, porém, apresentaram um certo grau de dificuldade na escrita e limitações na utilização do Google Classroom.

Todas as etapas da pesquisa tiveram feedbacks individuais para todos os estudantes por meio do comentário particular presente na plataforma, esses feedbacks estavam relacionados desde dúvidas na realização da atividade até questionamentos na utilização da plataforma. Durante todo o processo a professora ficou à disposição para auxiliá-los, sempre utilizando a ferramenta do comentário particular.

Para a análise dos relatos, consideramos os diferentes aspectos que emergiram das falas das crianças no sentido de identificar indícios do Letramento Estatístico. Deste modo, agrupamos aquelas que se aproximam em um conjunto de perspectivas semelhantes.

$\mathrm{Na}$ seção seguinte apresentamos a sequência de atividades $\mathrm{e}$ as análises desenvolvidas com a intenção de promover indícios do Letramento Estatístico em estudantes dos anos finais do Ensino Fundamental.

\section{DESCRIÇÃO, ANÁLISE E RESULTADOS DAS ATIVIDADES}

Entendemos que um dos aspectos desafiador em analisar narrativas de crianças consiste em "interpretar a interpretação da criança sobre suas experiências" (PASSEGGI et al., 2017, p. 468). Logo, as crianças possuem falas e escritas curtas que são carregadas de sentidos, as quais debate-se algumas delas.

A Atividade 1 foi intitulada "Dados estatísticos: novo coronavírus" e foi dividida em três etapas. A primeira etapa da Atividade 1 contou com a participação de 22 alunos. Nessa etapa os estudantes foram orientados a acessarem o site oficial do Ministério da Saúde (https://covid.saude.gov.br/) e coletarem dados referente ao número de casos confirmados e óbitos de cada Estado do Brasil para preencher uma tabela criada no Google Planilhas. 
Figura 1 - Planilha da Atividade 1

\begin{tabular}{|c|c|c|c|c|c|}
\hline Região & Estado & $\begin{array}{l}\mathrm{N}^{\circ} \\
\text { casos }\end{array}$ & $\begin{array}{c}\text { Total de } \mathrm{n}^{\circ} \text { de } \\
\text { casos por Região }\end{array}$ & $\begin{array}{l}\mathrm{N}^{\circ} \\
\text { óbitos }\end{array}$ & $\begin{array}{c}\text { Total de } \mathrm{n}^{\circ} \text { de óbitos por } \\
\text { região }\end{array}$ \\
\hline \multirow{7}{*}{ Norte } & Rondônia & & \multirow{7}{*}{ 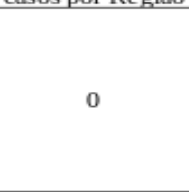 } & & \multirow{7}{*}{ 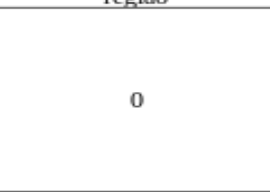 } \\
\hline & Acre & & & & \\
\hline & Amazonas & & & & \\
\hline & Roraima & & & & \\
\hline & Pará & & & & \\
\hline & Amapá & & & & \\
\hline & Tocantins & & & & \\
\hline \multirow{9}{*}{ Nordeste } & Maranhão & & \multirow{9}{*}{$\mathbf{0}$} & & \multirow{9}{*}{$\mathbf{0}$} \\
\hline & Piauí & & & & \\
\hline & Ceará & & & & \\
\hline & Rio Grande do & & & & \\
\hline & $\begin{array}{c}\text { Norte } \\
\text { Paraiba }\end{array}$ & & & & \\
\hline & Pernambuco & & & & \\
\hline & Alagoas & & & & \\
\hline & Sergipe & & & & \\
\hline & Bahia & & & & \\
\hline \multirow{4}{*}{ Sudeste } & Minas Gerais & & \multirow{4}{*}{$\mathbf{0}$} & & \multirow{4}{*}{$\mathbf{0}$} \\
\hline & Espírito Santo & & & & \\
\hline & Rio de Janeiro & & & & \\
\hline & São Paulo & & & & \\
\hline \multirow{3}{*}{ Sul } & Paraná & & \multirow{3}{*}{$\mathbf{0}$} & & \multirow{3}{*}{$\mathbf{0}$} \\
\hline & Santa Catarina & & & & \\
\hline & $\begin{array}{c}\text { Rio Grande do } \\
\text { Sul }\end{array}$ & & & & \\
\hline \multirow{4}{*}{$\begin{array}{l}\text { Centro } \\
\text { Oeste }\end{array}$} & $\begin{array}{l}\text { Mato Grosso do } \\
\text { Sul }\end{array}$ & & \multirow{4}{*}{$\mathbf{0}$} & & \multirow{4}{*}{$\mathbf{0}$} \\
\hline & Mato Grosso & & & & \\
\hline & Goiás & & & & \\
\hline & Distrito Federal & & & & \\
\hline
\end{tabular}

Fonte: dados da primeira pesquisadora.

Assim, a tabela teve como referência os estados brasileiros, as regiões, os números de casos confirmados, de casos confirmados por região, de óbitos e de óbitos por região. Dessa forma, orientamos os alunos a preencherem as colunas pintadas em amarelo e coletarem os somatórios automáticos das colunas que indicam o número total de casos confirmados e óbitos por região.

A maioria dos alunos preencheu a tabela de forma correta, entretanto, devido à dificuldade na utilização dos softwares, muitos optaram por copiar a tabela no caderno, preencher e tirar foto, além disso, alguns alunos que utilizaram a ferramenta não preencheram os campos solicitados, os próprios alunos acabaram fazendo a somatória, ignorando a configuração da tabela. A partir disso, podemos constatar uma dificuldade em trabalhar com o Google Planilhas e, consequentemente, uma defasagem no conhecimento tecnológico que é considerado uma das competências fundamentais e indispensável no currículo brasileiro (BRASIL, 2017). Essa verificação se tornou importante para direcionar o planejamento das próximas etapas da atividade.

Houve uma aluna que demonstrou dificuldade na compreensão do preenchimento da tabela, a coluna referente ao número de óbitos foi preenchida corretamente, porém a outra coluna, referente ao número de casos confirmados foi deixada em branco. A aluna entrou em contato, por meio do comentário particular da atividade, afirmando que não havia 
compreendido o que era para fazer. Diante disso, a professora auxiliou a estudante, porém a mesma não entrou mais na plataforma, deixando sua resposta incompleta. Outro caso, que pode ser classificado como uma dificuldade na hora de coletar os dados foi observado na atividade de um outro aluno que preencheu a tabela deixando algumas linhas em branco.

Assim, essa etapa foi importante para evidenciar a disseminação do vírus considerando que a cada dia os números de casos confirmados e óbitos aumentam e como os alunos preencheram em dias diferentes, se pode observar esse crescimento. Além disso, a atividade propõe uma coleta de dados por meio de um site oficial do Ministério da Saúde, deixando os alunos em contato com fontes confiáveis e atuais.

Nesse sentido Lopes (2008) afirma que o ensino de estatística torna-se promissor quando utilizamos dados reais, visto que os dados presentes no site são alterados diariamente, promovendo assim, a criação de séries temporais, referente ao dia da coleta de dados. Acreditamos que essa etapa contribuiu significativamente para uma discussão sobre o tipo mais adequado de gráfico para representar esses dados.

A segunda etapa da Atividade 1 contou com a participação de 15 alunos. Nessa etapa foi solicitado aos estudantes que a partir do preenchimento da tabela eles criassem dois gráficos que achassem mais adequados para, primeiramente, demonstrarem o número de óbitos por região e, em seguida, o número de casos confirmados por região. A orientação dessa etapa foi que eles criassem esses dois gráficos no caderno, tirassem fotos e anexassem na atividade correspondente. Foi solicitado que eles fizessem esses gráficos no caderno e não no software para que os gráficos que aparecem prontos não influenciarem suas escolhas. Dessa forma, a professora tinha como pretensão que eles escolhessem de fato os gráficos de acordo com os seus conhecimentos prévios e que julgassem mais adequados para os dados coletados, sem a influência dos gráficos mais usuais do programa.

A leitura inicial dos resultados mostrou que $90 \%$ dos alunos aderiram ao gráfico de colunas para representar seus dados propostos. De acordo com Diniz (2016) a estética dos elementos e a utilização mais comum do gráfico de colunas no dia a dia pode ter sido o elemento importante na escolha da estrutura de representação dos dados organizados pelos alunos.

Além disso, outras estruturas gráficas foram observadas nos resultados, dentre essas podemos citar o gráfico de colunas duplas, histograma, setores e por fim o gráfico de rosca. 
Essa diversidade de gráficos produzida pelos alunos pode estar relacionada aos diversos gráficos apresentados no site disponibilizado para a coleta de dados. Dessa forma, acreditamos que essa variedade apresentada no site conjugada com uma facilidade de reprodução do gráfico tenham sido os motivos para a escolha do tipo de gráfico a ser construído pelos alunos.

Dentre os gráficos apresentados pelos $6^{\circ}$ anos, a maioria dos alunos não utilizaram escala para representar as frequências e não consideraram a frequência relativa (Figura 2), o que de fato, impossibilitou uma comparação entre as regiões e uma compreensão real da proporção do vírus em determinada região, porque não foram considerados o número total de habitantes.

Embora o desenvolvimento da compreensão das escalas atrelada aos gráficos estatísticos na Educação Básica nem sempre é explorado em sala de aula pelos professores de forma intencional e sistemática, justifica a dificuldade dos alunos de localizar, analisar e comparar resultados. Além disso, a aprendizagem sobre escala tem sido uma das maiores dificuldades tanto de alunos como de professores na construção e interpretação de gráficos estatísticos (EVANGELISTA， 2014; AINLEY， 2000; GUIMARÃES， 2002; ALBUQUERQUE, 2010).

Figura 2 - Estratégias utilizadas por alunos do $6^{\circ}$ ano enviada pelo Google planilha.

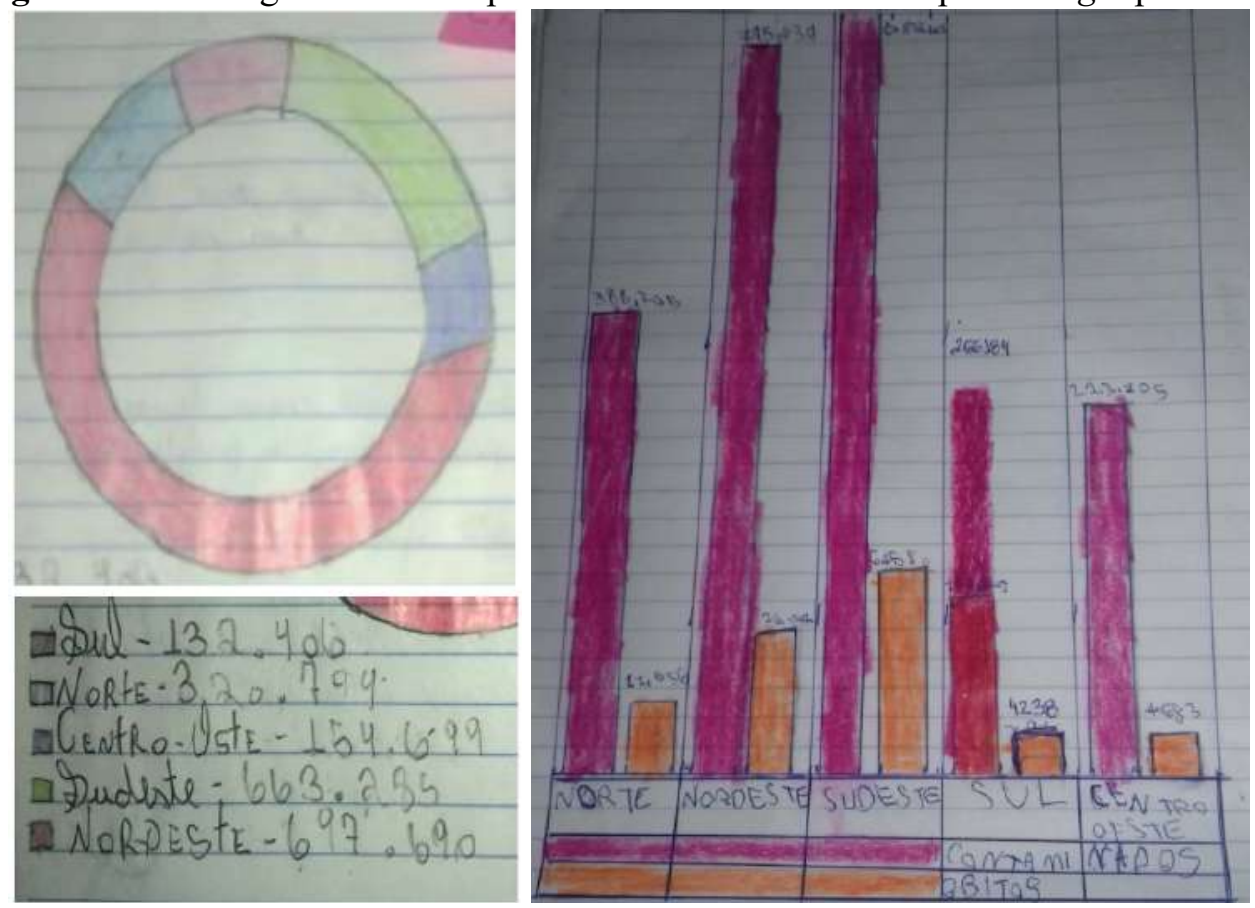

Fonte: dados da primeira pesquisadora. 
Alguns alunos não colocaram títulos e preencheram os eixos de forma incorreta, visto que uma aluna preencheu o eixo vertical em gráfico de colunas com os numerais de 1 a 9 , sem ter relação com os valores a serem representados. Duas outras estudantes criaram o gráfico de colunas utilizando como referência os estados, no eixo horizontal, e o número de óbitos ou casos confirmados, no eixo vertical, uma vez que solicitado o número de casos confirmados ou óbitos por região. Em contrapartida, houve alunos que fizeram os gráficos com escala, título e legenda (Figura 3), mas mesmo assim, não consideraram a frequência relativa, apenas utilizaram os valores presentes na tabela criada na etapa anterior.

Figura 3 - Estratégia utilizada por um aluno do $6^{\circ}$ ano enviada pelo Google Planilha.

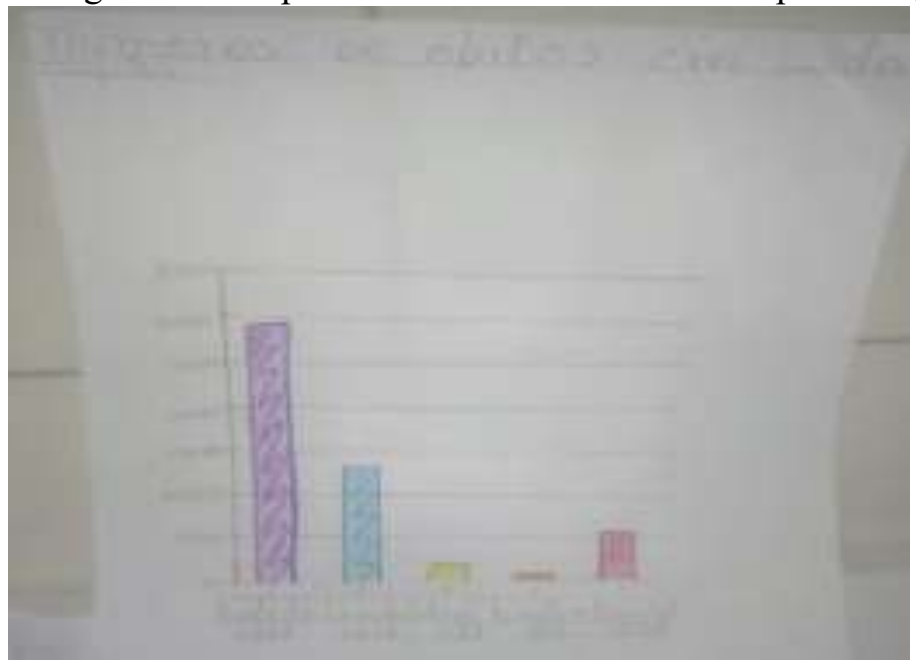

Fonte: dados da primeira pesquisadora.

Os alunos do $7^{\circ}$ ano apresentaram mais dificuldades no momento da compreensão da atividade proposta, visto que dos cinco alunos da turma que realizaram a atividade, três responderam à questão com a criação de tabelas por regiões, número de casos confirmados e número de óbitos. Ficando evidente que não compreenderam a proposta da atividade.

Essa etapa deixou em evidência as dificuldades que o professor deverá encontrar ao trabalhar com os seus alunos conteúdos referentes à construção de gráficos. Essas dificuldades observadas são importantes e podem promover um debate sobre a necessidade de se utilizar a escala de forma adequada e a consideração do total de habitantes de cada região, para então, se conseguir fazer comparações entre elas.

A terceira etapa da Atividade 1 contou com a participação de 17 alunos. Nessa etapa foi solicitado aos estudantes a produção de um texto, com base nas etapas anteriores, respondendo às seguintes questões: (1) Qual foi o tipo de gráfico criado por você? (2) Qual 
é o Estado que tem mais óbitos? (3) Qual é o Estado que tem mais casos? (4) Qual relação se pode fazer entre o Estado com mais casos e a região com mais casos? (5) Qual Estado tem menos casos? (6) Qual Estado tem menos óbitos? (7) Qual relação se pode fazer entre o Estado com menos casos e a região com menos casos? (8) Para responder às questões anteriores, você observou os gráficos ou a tabela? (9) Você considera que o gráfico facilitou a compreensão dos dados? Justifique sua resposta. Para então, justificarem como a Estatística pode ajudar na situação que estamos vivendo por causa do novo coronavírus. Nessa etapa da atividade a maioria dos alunos responderam às perguntas separadamente, ignorando a orientação de se criar um texto que contemplasse todas as respostas, ou seja, eles organizam seus pensamentos por meio de respostas curtas e fragmentadas, muitas vezes, sem fazer uma ligação entre as perguntas. Assim, após uma análise das respostas produzidas, identificamos que seus escritos convergiram para três perspectivas diferentes.

A primeira, são narrativas que apresentam indícios do Letramento Estatístico, nas quais podemos observar que a partir da atividade desenvolvida, o estudante refletiu sobre os dados (Quadro 1), os relacionou com a sua realidade e, a partir disso, assumiu uma postura de indignação, ou seja, os dados não foram desvinculados de seus contextos, e em todo o momento, ele sabia que os números representavam um estado de calamidade no país. Além disso, esse aluno conseguiu desenvolver um olhar crítico dentro do cenário de pandemia ao assumir um poder de decisão em suas atividades para tentar diminuir a quantidade de casos. Esse tipo de resposta demonstra que o estudante compreendeu como a Estatística tem uma função primordial em diversos setores da sociedade.

Quadro 1 - Respostas que apresentaram indícios do Letramento Estatístico "[...] ao preencher a tabela descobri a quantidade absurda de pessoas contaminadas e também a quantidade exagerada de pessoas que já perderam suas vidas por causa do vírus. [..] A Matemática pode me ajudar a ficar mais esperto, para que eu possa me cuidar melhor, e assim tentar diminuir a quantidade de casos" (Aluno do $6^{\circ}$ ano).

Fonte: Narrativas de aluno do $6^{\circ}$ ano enviada pelo google formulários

Podemos observar que a fala do aluno no (Quadro 1), após a construção da sua tabela, aponta indícios sobre a sua capacidade de extrair dados pontuais e de descobrir relações existentes entre os dados, o que de fato, lhe proporcionou uma visão mais ampla dos problemas enfrentados pela população brasileira ao relacionar os dados da tabela com o seu cotidiano. Assim, essa narrativa pode indicar indícios de uma leitura tabular de nível avançado (Nível 3) conforme descrita por Wainer (1995). 
A segunda, são narrativas que apresentam um olhar procedimental (Quadro 2), nas quais podemos observar que os gráficos facilitaram a compreensão dos estudantes. Porém, os alunos não fizeram reflexões sobre o que os dados representam, apenas os analisaram no sentido de responder as perguntas, sem fazer reflexões conscientes sobre a pandemia, quase os desvinculando de seu contexto. Esse tipo de perspectiva, diferente da anterior, tem como foco na matemática/estatística a possibilidade de criação de regras e procedimentos, sem fazer uma relação crítica da importância delas na vida em sociedade.

Quadro 2 - Respostas que apresentam um olhar que valoriza procedimentos

"Para responder às questões anteriores usei o gráfico e tabela (principalmente a tabela). O gráfico ajudou muito com minha compreensão, pois se não tivesse sido ela não teria conseguido responder muitas perguntas sem consultar a internet.

A matemática pode ajudar muito nesse momento de pandemia porque senão fosse ela como poderiam medir o número de mortes e contaminados por dia? Ou fazer um gráfico sobre o crescimento do vírus? A matemática faz parte do nosso dia-a-dia mesmo sem nós percebermos".

"Sim (referente ao gráfico ter facilitado a compreensão). Pois ele tem todas as informações que eu anotei" (grifo nosso).

Sim (referente ao gráfico ter facilitado a compreensão), porque eu não precisei pesquisar ou olhar um por um, pois todos já estavam no gráfico me ajudou muito".

Fonte: Narrativas de alunos do $6^{\circ}$ ano enviada pelo google formulários

A terceira, são narrativas que afirmam que os gráficos não foram relevantes para os alunos responderem as perguntas norteadoras dessa etapa (Quadro 3). Esses estudantes, demonstram que a atividade promovida não foi suficiente para suprir uma defasagem na habilidade de criar e interpretar gráficos, como é proposto em Brasil (2017), a qual foi sinalizada pelos próprios estudantes. Para essas crianças, a atividade proposta não promoveu avanços no desenvolvimento do Letramento Estatístico, evidenciando que cada estudante tem uma forma de compreensão. Deste modo, salientamos a importância do professor utilizar abordagens e estratégias diversificadas colocando os estudantes como protagonistas do seu conhecimento.

Quadro 3 - Respostas que não apresentam indícios do Letramento Estatístico

"Mais ou menos, (referente ao gráfico ter facilitado a compreensão), porque algumas coisas não estavam lá" (grifo nosso).

"Não (referente ao gráfico ter facilitado a compreensão) pra mim é muito difícil entender gráfico" (grifo nosso).

Fonte: Narrativas de alunos do $6^{\circ}$ ano enviada pelo google formulários 
Durante a análise dessa etapa, nós encontramos dois outros aspectos levantados pelos alunos que merecem destaque, o primeiro (Figura 4) está relacionado a consideração total da população da cidade de São Paulo, já o segundo, (Quadro 4) é referente a uma crítica tecida por um estudante sobre os gráficos apresentados pela mídia.

Apesar de os estudantes não considerarem o número total de habitantes por região ou estado na construção dos gráficos, um aluno ao responder às questões desta etapa sinaliza a importância de se utilizar o total de pessoas que habitam essa área, o que seria fundamental para a composição da frequência relativa (Figura 4).

Figura 4 - Resposta que apresenta indícios da importância da Frequência relativa na análise de dados.

O estado de s3a Paulo encontra-se com maior número de casos da doença contado apenas cocn ele por set um estado muito populoso e cheio de habitante em relaçjo a regiäo com mais casos por se menos populosa somando um número muito alto como a regiăo norte

Fonte: Narrativa de aluno do $7^{\circ}$ ano enviada pelo google formulários

A narrativa apresentada pelo aluno (Quadro 4) evidencia como o gráfico criado por ele facilitou a compreensão das ideias, mesmo não sendo o gráfico mais recomendado para esse tipo de variável, foi significativo no auxílio da produção do texto. Além disso, vale ressaltar que o estudante tece uma crítica em relação ao gráfico considerado mais adequado, o gráfico de linhas (por ser abordada uma série temporal), que é o utilizado pela mídia na divulgação dos dados. A partir dessa resposta, podemos considerar que a atividade contribuiu para que o aluno conseguisse responder corretamente às perguntas direcionadoras dessa etapa.

Quadro 4 - Resposta que apresenta uma crítica com relação aos gráficos presentes na mídia.

[...] para responder essas coisas eu tive que rever o gráfico, com o gráfico facilita a compreensão dos dados porque fica mais fácil de ver porque não é igual os gráficos dos jornais que passa na TV porque aqueles com uma linha acima da outro que acaba dificultando as pessoas entenderem, com a matemática ajuda as pessoas entenderem os gráficos os profissionais de saúde saberem o número de leitos ocupados e etc.

Fonte: Narrativa de aluno do $7^{\circ}$ ano enviada pelo google formulários

A Atividade 2 intitulada "Reflexões sobre o retorno às aulas presenciais" foi dividida em três etapas.

A primeira etapa contou com a participação de 14 alunos. Essa etapa tinha como característica utilizar os recursos de interação (mural) entre os estudantes. Dessa forma, foi solicitado que eles respondessem três perguntas no mural e depois comentassem as respostas 
dos outros colegas, a fim de trocar ideias e pontos de vistas. Para o desenvolvimento dessa etapa, foram disponibilizados três vídeos de reportagens sobre a pandemia no país e uma apresentação com os protocolos de segurança que todas as escolas devem garantir para o retorno das aulas presenciais em todo o território do Estado de São Paulo, a fim de proporcionar uma reflexão sobre a situação atual.

As perguntas norteadoras desta etapa foram: (1) "Você acredita que agora é o momento certo para o retorno das aulas presenciais? Se não, qual é o melhor momento?”; (2) "Pensando nos protocolos de segurança e na realidade da sua escola. Você considera possível todos esses protocolos serem seguidos? Justifique sua resposta” e "(3) Se as aulas retornassem agora, você iria voltar para a escola? Por quê?”. Entretanto, a maioria dos estudantes não conseguiram postar suas respostas no mural e, consequentemente, não houve interação entre eles. Os estudantes enviaram suas respostas por meio de comentários particulares diretamente para o professor, momento assíncrono.

Para a pergunta (1) todos os alunos responderam que acreditam não ser o momento de retorno às aulas presenciais, suas justificativas são que muitos alunos não irão respeitar as orientações de distanciamento e acabariam se aglomerando, fazendo com que todos os alunos ficassem expostos ao risco de contrair a doença. Além disso, seria perigoso que esses estudantes transmitissem a doença para seus familiares, os quais muitos se enquadram nas características do grupo de risco para a COVID-19.

Assim, os alunos justificaram que esse retorno às aulas acarretaria no aumento nos números de casos e mortes da população como um todo, visto que mais pessoas sairiam do isolamento social, mais alunos indo para a escola e seus responsáveis os levando e buscando. A maioria dos alunos justificaram que se as aulas retornassem hoje (3) eles voltariam só 2021, quando forem vacinados, ou quando o número de casos/óbitos se estabilizarem. Entretanto, nos deparamos com alguns relatos de alunos que voltariam por saudade dos amigos.

Com relação ao questionamento sobre os protocolos de segurança (2), a maioria dos estudantes afirmaram que não poderiam ser seguidos por conta dos próprios alunos, que não respeitam as recomendações de limpezas, com exceção de uma narrativa que criticou a falta de funcionários na escola, afirmando que não teriam pessoas suficientes para limpar todos os locais que eles encostassem.

ReviSeM, Ano 2021, N. 1, p. $169-190$ 
A segunda etapa contou com a participação de 17 alunos. Semelhante a etapa anterior, também teve característica de utilizar os recursos de interação, entretanto, nesse caso, foi utilizado o Google Planilhas (Figura 5). Assim, foi criado o mesmo documento para as quatro turmas envolvidas na pesquisa. Essa etapa consistia em preencher a planilha eletrônica com o nome e as respostas das perguntas anteriores, utilizando apenas sim ou não. Essa etapa se tornou importante para sintetizar as respostas dos alunos e para a criação do formulário da etapa seguinte.

A terceira etapa contou com a participação de 27 alunos. Foi criado um formulário (https://forms.gle/eEnDKzfqG9mRvbXu5) com a representação gráfica das respostas dos estudantes preenchidas na planilha eletrônica para que os alunos pudessem refletir sobre a visão de seus colegas, para então escrever um texto a partir do seguinte enunciado: "Utilizando as suas respostas e a dos seus colegas (observadas pelos gráficos), os vídeos e as reportagens. Escreva uma carta para o Prefeito da Cidade de São Paulo, justificando se você acredita que é o momento certo para o retorno das aulas presenciais. Lembre-se de argumentar de forma convincente e com os dados obtidos. O texto deve conter no mínimo 10 linhas”. A exigência de uma quantidade mínima de linhas foi para combater respostas curtas que apresentam poucas argumentações, fazendo com que os estudantes reflitam mais sobre as informações estatísticas apresentadas.

Essa etapa contribuiu para a visualização da evolução dos alunos no caminho para o Letramento Estatístico, visto que baseado em informações coletadas, organizadas e interpretadas tomaram decisões pautadas em dados. Deste modo, após a análise dos relatos das crianças (ver Quadro 5) observamos o apontamento que não era o momento do retorno às aulas, tomando como base os resultados da pesquisa feita em sala de aula articulada com seus conhecimentos sobre a gravidade da situação. Nessa direção, outra preocupação relevante apontada pela maioria dos estudantes está associada com a possibilidade de propagação do vírus e a contaminação de pessoas com comorbidades com o retorno às aulas e com a inquietação da aprovação de uma vacina.

Um aluno aponta indícios relacionados à "taxa de curados" que é a razão entre o número absoluto de curados pelo de casos que contraíram o vírus, em seguida, outro aluno considera que a pesquisa foi feita por pequena amostra limitada a população estudada, no entanto, faz inferências articulando esses resultados com suas vivências, diferenciando uma 
pesquisa amostral da censitária como sugere Brasil (2017). Além disso, toma a sua decisão com base em notícias veiculadas na mídia sobre a gravidade da doença e possivelmente com informações sobre a opinião de outros colegas que estudam em escolas diferentes. Por outro lado, além dos resultados já obtidos em sala de aula, outro aluno procura elementos externos como a taxa de infectados na cidade de São Paulo para argumentar e fundamentar sua decisão.

Quadro 5 - Cartas produzidas pelos alunos para o Prefeito da Cidade de São Paulo.

Caro Bruno Covas, 31/08/20

Venho a fazer está carta para dizer que acho que não é o momento correto para voltar as aulas presenciais, pois a pandemia ainda é alarmante e muitos pais e responsáveis não irão mandar as crianças/adolescentes para a escola com medo de pôr a vida do jovem em risco e os que moram junto com eles.

A escola Joaninha Grassi Fagundes, na Brasilândia, Zona Norte propôs uma pesquisa com os alunos, e muitos (assim como eu) considera que não (82\%) (que pensando nos protocolos de segurança e a realidade da escola, você considera possível todos seguirem os protocolos de segurança.

Espero a vacina chegar, ou até tiver pequenos casos e mortes no estado. Y.O.R., $6^{\circ} \mathrm{B}$.

eu acho que não é um momento correto para retorne as aula presenciais pois o números de curados (3.278.243) ainda não ultrapassou o número de casos (4.091.801) então eu recomendo que os alunos ficassem em casa e espera-se mais um pouco até esse número de recuperados ultrapassar o número de casos ou então encontra uma cura ou medicação ou até mesmo vacina contra o coronavírus enquanto isso não acontecer é bem melhor os alunos ficarem em casa seguindo e respeitando a quarentena do que correr risco de contaminar os alunos, professores, funcionários e etc. ou até mesmo pegar o vírus sem contar o risco de contaminar a família do aluno em fim é melhor os alunos ficarem em casa e esperar um pouco mais para que o número de óbitos (125.584) não aumente mais ainda ;)

Sr. Prefeito, na minha opinião, as aulas presenciais só deveriam começar depois da vacinação, pois isso não depende somente dos professores e coordenadores, é essencial a colaboração dos alunos, e manter distância pode ser muito difícil para jovens que passaram meses sem contato com seus colegas, e isso pode expor alunos e seus responsáveis ao vírus, causando mortes de jovens e idosos. A taxa de infectados em São Paulo passa de $300 \mathrm{mil}$, e se as aulas presenciais voltarem sem uma vacina, sem a garantia que muitas pessoas não seriam infectadas, muitos irão morrer, e a taxa de mortes em São Paulo pode passar de 15 mil para 20 mil, ou até 30 mil. Seria muito mais vantajoso acelerar o procedimento de testes e de distribuição da vacina contra o covid-19, para que todos possam voltar as suas rotinas normal. Não adianta estudar por 2 meses e morrer depois de 2 semanas. A maioria dos estudantes não participarão das aulas presenciais, e não tem escolas sem alunos, com isso não vale a pena.

Fonte: Narrativas de alunos do $6^{\circ}$ e $7^{\circ}$ anos enviadas pelo google formulários

A atividade 3 intitulada "A realidade da minha escola" foi dividida em três etapas e, como mencionado anteriormente, foi reduzida sua aplicação a apenas uma turma do $7^{\circ}$ ano. Devido a essa redução de turmas, houve uma queda significativa na quantidade de 
devolutivas dos estudantes.

A primeira etapa contou com a participação de oito alunos e consistiu na leitura da reportagem intitulada "Covas descarta aulas e atividades de reforço em setembro na capital", que traz à tona o recorte: "De acordo com os dados, $16,1 \%$ dos alunos da rede pública municipal já contraiu a doença causada pelo novo coronavírus. O índice é maior do que o encontrado na população geral de São Paulo, que foi de 10,9\% de infectados" e "Um dos resultados que levou a prefeitura a optar por não reabrir as escolas em setembro é que 64,4\% dos estudantes - isto é, cerca de 2 a cada 3 alunos - são assintomáticos", para então, responderem a um formulário, disponível em https://forms.gle/qBeTYqgav2Ga22zs6, que aproximava esses dados para a realidade da escola deles, todos os valores percentuais da entrevista foram solicitados que os estudantes aplicassem na quantidade total de alunos da escola (aproximadamente 270 alunos).

Além disso, o formulário também contava com algumas perguntas que os fizessem refletir sobre a possibilidade de colegas infectados. Ao final deste formulário, foi solicitado o seguinte: "Agora vamos pesquisar se esses dados se enquadram na realidade da nossa escola? Vamos fazer um formulário para que todos os alunos respondam: Qual pergunta você acha importante fazermos? Pode dar mais de uma sugestão. (Utilize como base esse formulário e as reportagens estudadas na Atividade 2)", para fazer um formulário que investigue as particularidades dos estudantes da escola. Esse formulário foi disponibilizado para todos os alunos da escola, conta com seis perguntas e pode ser respondido anonimamente.

As atividades deste artigo ainda estão em andamento, com o passar do tempo, a devolutiva dos estudantes têm diminuído significativamente, então as atividades são desenvolvidas em um tempo maior. Atualmente, o formulário continua disponível para todos os alunos da escola sem nenhuma devolutiva.

A segunda etapa da Atividade 3 consistirá na análise dos dados coletados e, a partir desses dados, a construção de uma reportagem relacionando todas as atividades e abordando a pandemia em âmbito nacional, estadual, municipal e local, visto que os alunos terão os dados dos seus próprios colegas.

A terceira etapa da Atividade 3 é a finalização da sequência de atividades que será a divulgação da pesquisa realizada pelos estudantes dessa escola para toda a comunidade por 
meio da rede social da escola, facebook.

\section{CONSIDERAÇÕES FINAIS}

Vale relembrar que nosso estudo tem por intuito a promoção de indícios de Letramento Estatístico em estudantes da educação básica, contribuindo para a tomada de decisão com base em informações estatísticas relacionadas ao coronavírus, isolamento social e retorno das aulas presenciais.

A aplicação da sequência de atividades tomou como base as exigências contidas em Brasil (2017) e colaborou para uma postura de investigação para além do que foi solicitado. Deste modo, a partir dos apontamentos presentes nas análises realizadas, entendemos que houve uma contribuição para o desenvolvimento do Letramento Estatístico em alguns desses estudantes, uma vez que observamos a presença do pensamento crítico na tomada de decisões estatísticas frente a problemas reais.

Diante disso, o desenvolvimento desse pensamento crítico dos alunos e seu papel de protagonista na resolução das atividades associadas ao contexto atual foi motivado por considerar uma problemática em evidência. De fato, a abordagem proposta contribuiu para iniciação à investigação estatística, ampliação na leitura de gráficos e tabelas, resolução de problemas associados ao cotidiano. Além disso, permitiu que desenvolvessem textos a partir dos resultados estimados conforme Brasil (2017), provocando reflexões sobre suas crenças e concepções do problema apresentado.

A sequência desenvolvida contribuiu para uma articulação da Matemática/Estatística com base numa área associada a ciências. De fato, as análises evidenciam uma vinculação entre os resultados e a possibilidade ou não do retorno das aulas nesse momento. Portanto, observamos que houve uma ampliação na capacidade de argumentação sobre os resultados estimados com apoio de informações sobre o novo coronavírus.

Em suma, esperamos que essa sequência de atividades possa ser útil como uma estratégia de ensino da estatística para professores dos anos finais do Ensino Fundamental, tendo como foco a temática do novo coronavírus com objetivo de desenvolver o letramento estatístico. Assim, espera-se que a sequência possa ser aplicada em outras escolas com o intuito de promover novas atitudes, como por exemplo, a importância do uso da máscara e do distanciamento social, de modo que, alunos e professores, possam ter um olhar crítico 
sobre os dados veiculados na sociedade para tomar decisões coerentes.

\section{REFERÊNCIAS}

AINLEY, J. Exploring the transparency of graphs and graphing. In T. Nakahara \& M. Koyama (Eds.), Proceedings of the 24th Annual Conference of the International Group for the Psychology of Mathematics Education, vol. 2, pp. 9-16, Hiroshima, Japão, 2000.

ALBUQUERQUE, R. G. C. Como adultos e crianças compreendem a escala representada em gráficos (Dissertação de mestrado). Universidade Federal de Pernambuco, Recife, 2010 .

BRASIL. Ministério da Educação. Secretaria de educação Fundamental. Parâmetros Curriculares Nacionais: Matemática. Terceiro e quarto ciclos do Ensino Fundamental. Brasília: MEC/SEF, 1997.

BRASIL. Base Nacional Comum Curricular. http: //www.mec.gov.br/, 2017. Disponível em:

$<$ Http://portal.mec.gov.br/index.php?option=com_docman\&view $=$ download\&alias $=79601$ -anexo-texto-bncc-reexportado-pdf-2\&category slug=dezembro-2017pdf\&Itemid=30192>. Acesso em: 02 Maio 2019.

CAMPOS, C. R.; WODEWOTZKI, M. L. L.; JACOBINI, O. R. Educação Estatística: teoria e prática em ambientes de modelagem matemática. Belo Horizonte: Autêntica editora, 2011.

CASATTI, D. Ensino remoto na pandemia pode transformar educação. Jornal da USP. São Paulo, 26 mai. 2020. Disponível em < https://jornal.usp.br/universidade/ensino remoto-na-pandemia-pode-transformar-educacao/> Acesso em 10 de nov. de 2020.

CAZORLA, I. M.; KATAOKA, V. Y.; SILVA, C. B. D. Trajetórias e perspectivas da educação estatística no Brasil: um olhar a partir do GT12. 1. ed. Campinas: Mercado de Letras, 2010. v. I.

DINIZ, L. N. Leitura, construção e interpretação de gráficos estatísticos em projetos de modelagem matemática com uso das tecnologias de informação e comunicação. Tese de Doutorado, Universidade do Minho, Braga, 2016.

EVANGELISTA, M. B., GUIMARÃES, G. L. Escalas representadas em gráficos: Um estudo de intervenção com alunos do $5^{\circ}$ ano. Revista Portuguesa de Educação, Braga, v. 28, n. 1, p. 117-138, jun. 2015.

GAL, I. Adults' Statistical Literacy: Meanings, Components, Responsibilities.

International Statistical Review, p. 1-51, 2002.

GUIMARÃES, G. L. Interpretando e construindo gráficos de barras (Tese de Doutorado). Universidade Federal de Pernambuco, Recife, 2002.

LOPES, C. E. O ensino da estatística e da probabilidade na educação básica e a formação dos professores. Cad. Cedes, Campinas, v. 28, p. 57-73, 2008. Disponível em: $<$ https://www.scielo.br/pdf/ccedes/v28n74/v28n74a05.pdf >. Acesso em: 03 jan. 2020.

LOPES, C. E. Os desafios para educação estatística no currículo de matemática, in LOPES, 
Celi Espasandin; COUTINHO, Cileda de Queiroz e Silva; ALMOULOUD, Saddo Ag (Orgs). Estudos e reflexões em educação estatística. Campinas: Mercado de Letras, p. 4763, 2010.

MINAYO, M. C. S. Pesquisa Social: teoria, método e criatividade. 29. ed. Petrópolis: Editora Vozes, 2010.

PASSEGGI, M. D. C. et al. Narrativas autobiográficas com crianças na pesquisa qualitativa em educação: reflexões sobre procedimentos de análise. $6^{\circ}$ Congresso Ibero Americano de Investigação Qualitativa em Educação. [S.l.]: [s.n.]. 2017. p. 468-477.

WAINER, H. A study of display methods for NAEP results: I. Tables. ETS Research Report Series, v.1995, n.1, 1995. 